\title{
A crítica à abstração e à representação no imaterialismo de Berkeley
}

\author{
M aria Adriana C amargo C appello \\ doutoranda na Universidade de São Paulo
}

\begin{abstract}
resumo 0 presente texto tem por objetivo examinar as relações existentes entre a crítica às idéias abstratas, apresentada por Berkeley na "Introdução" ao Tratado sobre os princípios do entendimento humano, e a argumentação desenvolvida nos primeiros parágrafos da Parte I do mesmo texto, em que o autor propõe seu imaterialismo. A hipótese levantada a partir de tal exame defende uma relação direta entre o nominalismo de Berkeley e o caráter inaceitável, para 0 autor, da distinção entre 0 ser e 0 aparecer da matéria postulada pelas teorias da representação.
\end{abstract}

palavras-chave idéias abstratas - nominalismo - imaterialismo - representação

Berkeley denuncia, na "Introdução" ao Tratado sobre os prinápios do conhe imento humano (BER KELEY, 1979), os maus usos da linguagem que teriam como conseqüência muitos dos erros cometidos pelos "sábios". Com efeito, o maior desses erros seria o da postulação de uma natureza das coisas distinta de sua percepção, erro que, por sua vez, seria sustentado por um pressuposto equivocado em relação aos termos gerais da linguagem. Berkeley trata desse tema a partir das considerações sobre as idéias abstratas presentes no E nsaio sobre o entendimento humano de Locke (1979) - cujas citações são literais nos Prinápios -, posicionando-se diante da questão sobre se a generalidade seria uma propriedade das idéias ou uma relação estabelecida pelos termos da linguagem. Berkeley - e, depois dele, H ume (2000) - apóia-se na constatação de que, para que uma idéia pudesse ser geral, ou seja, para que ela fosse uma representação abstraída R ecebido em dezembro de 2004. A ceito em janeiro de 2005. doispontos, Curitiba, vol. 1, n. 2, p.57-73, jan/ jun, 2005 
de várias idéias particulares, seria preciso que ela separasse o inseparável, ou seja, que ela separasse cada quantidade ou qualidade da determinação particular que a constitui. Assim, para conceber a cor em geral, seria preciso não pensar em cor alguma, dado que, para pensar uma cor, é preciso pensá-la em sua determinação particular e pensar uma determinação particular é excluir todas as demais. No mesmo sentido, para pensar uma linha em geral, seria preciso separá-la de sua extensão quantificada e da qualidade pictórica em que essa extensão é expressa. N o entanto, 0 que seria a linha sem sua extensão, cor e forma, que têm sempre de darse em graus determinados? Sendo assim, a crítica à capacidade da abstração, ou à possibilidade de conceber idéias gerais abstratas, fundamenta-se tanto na determinação individual dos objetos - o que, em última instância, apóia-se no próprio princípio de não-contradição e na inseparabilidade, neles, do que é indistinguível ${ }^{1}-$, quanto na relação existente entre esses objetos e a capacidade de a mente representá-los por meio de idéias por ela mesma produzidas. Essa capacidade, para Berkeley e também para $\mathrm{H}$ ume, resume-se à construção de idéias que, mesmo indo além da reprodução estrita daquilo que se percebe como existente no mundo, não pode ir além das possibilidades de percepção desses objetos, uma vez que ambos não admitem que o entendimento possa separar aquilo que efetivamente não pode ser percebido separadamente.

Segundo essa concepção, a predicabilidade dos termos gerais dá se não por intermédio de uma idéia geral, mas pelo estabelecimento de uma relação que se efetiva na ampliação da extensão desse termo, ou seja, um termo geral corresponde a todas aquelas idéias particulares que reconhecemos possuírem qualidades semelhantes. Tal semelhança, no entanto, é constatada posteriormente à própria constatação daquilo que existe em cada indivíduo, portanto não pode se dar como algo existente "fora" ou "subjacente" a cada indivíduo. Segundo tal concepção, portanto, cada indivíduo torna se, por suas qualidades mesmas, um signo dos demais.

$\mathrm{N}$ o entanto, se Berkeley e H ume estão do mesmo lado na questão da generalidade dos termos, negando que eles tenham como referência idéi as abstraí das daquilo que as caracterizaria particularmente, a principal conseqüência retirada por Berkeley desse nominalismo, e que obviamente não será comungada por H ume, é seu próprio imaterialismo. Em outras palavras, Berkeley usará a impossibilidade de separar, por exemplo, a cor 
da extensão e da forma em que essa cor é percebida e a impossibilidade de dar sentido aqueles termos que costumam ser considerados características próprias da matéria - como "extensão", "forma" e "movimento" sem uma referência precisa dada na percepção para evidenciar o contra senso em postular a existência dessa matéria para além de suas determinações sensíveis.

Percorrendo esse trajeto que se inicia na "Introdução" e concretiza-se no que ele tem de essencial logo nos primeiros parágrafos da Parte I dos P rinápios, acreditamos poder traçar as relações existentes entre a crítica à teoria da abstração e o imaterialismo de B erkeley, o que, necessariamente, implica uma crítica às teorias da representação. Isso porque a crítica à substância material é justamente a crítica àquela realidade que existiria para além de nossas percepções sensíveis, substância que, nesse sentido, poderia ser conceituada por meio de uma idéia que abstraísse dessas percepções sensíveis - o que, em última instância, equivale à própria crítica a essa duplicidade entre matéria e percepção da matéria inerente às teorias da representação.

A pós ter afirmado, nos primeiros parágrafos da "Introdução" aos P rinćpios, sua fé na possibilidade do conhecimento humano, ou seja, sua fé na adequação das capacidades do entendimento à natureza dos objetos sobre os quais ele se debruça, contra todas as dúvidas levantadas por aqueles que abandonam o bom senso e, com isso, afastam-se "dos sentidos e dos instintos para refletir sobre a natureza das coisas" (BER KELEY, 1979, $\S 1$ o), Berkeley pergunta-se se não teria sido a escolha de princípios erra dos a causa de tanto ceticismo e propõe-se a investigar em que princípios o conhecimento humano poderia apoiar-se.

M as, para tanto, Berkeley entende serem necessários al guns esclarecimentos preliminares sobre a natureza e os maus usos da linguagem. Tais esclarecimentos, que serão a matéria mesma dessa "Introdução", levá- loão a adiantar parte de sua investigação, uma vez que justamente um dos maus usos da linguagem, em questão, implica a possibilidade de a mente construir idéias abstratas e noções de coisas; essa concepção seria responsável por muitas, senão pela principal, dificuldade em que se encontra envolvido o conhecimento humano. Centremo-nos então, primeiramente, na descrição e, posteriormente, na crítica feita por Berkeley às idéias abstratas. 
De início, Berkeley lembra-nos de que todos estão de acordo com o fato de que as qualidades dos objetos existem apenas em conjunto nos objetos e que, no entanto, aqueles que afirmam a capacidade de construir idéias abstratas afirmam a capacidade de a mente tomar isoladamente essas qualidades e torná-las, cada uma separada das demais, conteúdo de uma idéia. Assim, a mente poderia, ao observar um objeto extenso, colorido e móvel, considerar isoladamente cada uma dessas qualidades e construir uma idéia de extensão sem cor, de cor sem extensão e de movimento sem a consideração de qualquer corpo extenso e colorido.

A té aqui estaríamos em um primeiro nível de abstração, o da separação, em idéias simples e individuais, daquelas qualidades que só existiriam em um individual complexo. M as o processo da abstração, segundo a descrição de Berkeley, poderia ainda se dar em um outro nível, ou seja, a partir da observação, por exemplo, em várias daquelas extensões tomadas separadamente das outras qualidades com as quais elas aparecem em conjunto, de algo que seria comum e semelhante a todas elas e da possibilidade de separação disso que seria comum daquilo que seria peculiar a cada uma, como uma determinada forma e um determinado tamanho. D eixando de lado, então, aquilo que caracterizaria particularmente cada uma das extensões e levando em conta apenas aquilo que é comum a todas, seria possível construir a idéia muito mais abstrata de extensão em geral. Tal extensão não seria grande ou pequena, não se configuraria como uma linha, um sólido ou um plano, dado que cada uma dessas determinações pertence às extensões particulares das quais essa idéia de extensão teria sido abstraída. 0 mesmo ocorreria em relação à cor e ao movimento. A idéia abstrata de cor não poderia ser a do azul, do amarelo ou do vermelho, mas seria a idéia daquilo que é comum tanto ao azul quanto ao amarelo, vermelho ou qualquer outra cor particularmente definida. 0 movimento, da mesma forma, não poderia ser lento nem rápido, nem ser considerado em nenhuma trajetória definida.

Bem - continua Berkeley -, no mesmo sentido em que seria possível construir uma tal idéia abstrata de modos ou qualidades, também seria possível construir uma idéia abstrata de algo mais complexo que se apresentasse como um conjunto dessas qualidades assim abstraídas. D esse modo, considerando os indivíduos John, Peter e James e abstraindo de cada um deles aquilo que lhes é comum e desconsiderando o que é 
peculiar a cada um, seria possível construir a idéia abstrata de homem, humanidade ou natureza humana da qual cada homem particular participaria. Tal idéia teria de envolver uma cor, dado que todo homem tem uma cor, mas ela não poderia ser branca, nem preta nem amarela, uma vez que nenhuma dessas cores é comum a todos os homens. Também teria de envolver um tamanho que, no entanto, não poderia ser al to, nem baixo, nem mediano, dado que nenhum desses tamanhos é comum a todos os homens. Seguindo por esse caminho da abstração do que é comum a um número determinado de indivíduos daquilo que é particular a cada um deles, chegaríamos a idéias ainda mais gerais, como a de animal e a de ser vivo. B erkeley insiste mais uma vez: se a idéia de animal inclui a idéia de corpo, sentidos e movimento espontâneo, esse corpo não poderia ser considerado sob nenhuma forma ou aparência determinada; por exemplo, não poderia ser considerado como coberto seja por pêlos, penas, escamas ou mesmo como não possuindo nenhum tipo de cobertura, uma vez que tanto pêlos, penas, escamas ou a falta deles são determinações de corpos particulares. Também o movimento espontâneo que caracterizaria a idéia de animal não poderia ser voar, andar ou rastejar e assim por diante.

Terminada a descrição do processo de abstração segundo aqueles que a defendem, Berkeley fará a crítica a essa capacidade de abstração apresentando o seu próprio modo de "abstrair".

Logo de início, B erkeley distingue-se da posição que ele deseja criticar ao reafirmar o princípio empirista por excelência, aquele que estabelece como fonte de nossas idéias as percepções sensíveis, e dá-lhe contornos bastante definidos. Sendo assim, no lugar da capacidade da abstração ou da construção de noções, Berkeley afirma a capacidade que a mente possui de representar ou imaginar as coisas particularmente percebidas por meio de idéias e de, então, dividi-las e compô-las entre si de diversos modos: "Se outros têm essa extraordinária faculdade de abstrair suas idéias, só eles podem dizer; quanto a mim, sei apenas que tenho a faculdade de imaginar, ou representar idéias daquelas coisas particulares que eu tenha percebido e de compô-las e dividi-las de inúmeros modos" (idem, § 10).

N o entanto, essa capacidade de dividir ou separar os objetos particularmente percebidos dá-se na medida mesma da possibilidade de eles assim apresentarem-se na percepção, ou seja, mantendo suas determi- 
nações particulares. O ra, uma vez que, "como todos concordam", as qualidades só podem existir em conjunto nos objetos - o que significa dizer que elas só se apresentam em conjunto e segundo determinações particulares -, a capacidade de a mente separar, ou abstrair as idéias umas das outras, não poderá dar-se nesse nível. Assim, B erkeley concede que pode imaginar a cabeça, as mãos, os olhos, o nariz separados do restante do corpo de um homem; no entanto, cabeça, mãos, olhos e nariz, por terem sido anteriormente apresentados como um determinado conjunto de qualidades, têm de ser imaginados com essas qualidades, ou seja, têm de ter uma certa forma, um certo tamanho e uma certa cor. D o mesmo modo, Berkeley afirma que a idéia de homem que ele é capaz de construir tem de incluir uma determinada cor, uma determinada forma com as quais esse homem assuma uma determinada posição em relação ao que o cerca, assim como qualquer idéia de movimento que ele possa construir para si tem de representar um movimento lento ou rápido, retilíneo ou curvilíneo - ou seja, tem de possuir aquelas características que the dão a individualidade da percepção. Berkeley conclui, portanto, poder abstrair apenas no sentido em que pode separar em pensamento coisas que, mesmo existindo unidas, poderiam existir separadas umas das outras, não sendo absolutamente capaz de separar aquelas qualidades que não podem existir assim separadas ou, ainda, que é absolutamente incapaz de formar noções gerais de coisas a partir da abstração das peculiaridades dadas em várias coisas particulares.

Em resumo, B erkeley apresenta a capacidade da abstração, a ser criticada, como a da separação em idéias simples desses modos ou qualidades que só existem em conjunto nos objetos e, mais do que isso, da separação desses modos ou qualidades de sua caracterização particular, ou seja, daquilo que os constitui enquanto tal. É diante dessa caracterização de abstração que ele apresenta sua objeção, calcada, em primeiro lugar, no argumento empirista da origem sensível de nossas idéias - e, como tal, em um princípio também defendido por Locke. $\mathrm{N}$ o entanto, apesar dessa concepção empirista comum a ambos, Berkeley, em um movimento que se repete inúmeras vezes no decorrer do texto, distancia se radicalmente de Locke ao negar que a mente seja capaz de produzir qualquer idéia que não tenha como correlato uma percepção, ainda que apenas possível. Assim, para Berkeley, da mesma forma como não é possível perceber uma 
cor fora de uma determinada extensão delimitada por uma determinada forma e tamanho, não é possível conceber a idéia de cor separada das de extensão, forma e tamanho. Por outro lado, assim como todos os seres percebidos são particulares, ou seja, têm suas qualidades e quantidades particularmente definidas, a mente não é capaz de construir idéias dessas qualidades e quantidades separadas de suas determinações particulares - 0 que envolveria um desrespeito ao próprio princípio de não-contradição, invocado por H ume posteriormente: "R econhece-se que nenhum objeto pode aparecer aos sentidos, ou, em outras palavras, que nenhuma impressão pode se tornar presente à mente, sem ser determinada em seus graus, tanto de quantidade quanto de qualidade. A confusão que por vezes envolve as impressões procede somente de sua fraqueza e instabilidade, e não de uma capacidade que teria a mente de receber uma impressão que, em sua existência real, não possua um grau ou proporção particulares. I sso seria uma contradição em termos, e implicaria a mais absoluta das contradições, a saber, que é impossível que uma coisa seja e não seja" (HU ME, 2000, livro I, parte I, sec.VIII).

M as, então, Locke, apesar de conceder ser a experiência a única fonte de nossas idéias e que as qualidades dos objetos percebidos só podem existir em conjunto neles - além de, obviamente, não ter qualquer intenção de desrespeitar o princípio de não-contradição - não levaria nada disso em conta ao admitir a possibilidade, por exemplo, da idéia de branco abstraída de qualquer outra? Com efeito, em defesa de Locke, poderíamos remeter-nos às suas considerações sobre as idéias simples, no Livro II do E nsaio, quando ele propõe que, apesar de unidas nos objetos, as idéias de cor e de movimento, percebidas ao mesmo tempo pela visão, afetam os sentidos separadamente e, dessa forma, são tão distintas uma da outra quanto duas qualidades - por exemplo a cor e o perfume de um lírio - que são percebidas por dois sentidos diferentes. "Ainda que as qualidades que afetam nossos sentidos estejam tão unidas umas às outras nas coisas de modo que não há separação ou distância entre elas, é evidente que as idéias que elas produzem na mente entram pelos sentidos de forma não composta. [...] A frieza e a dureza que um homem sente em um pedaço de gelo [...] são, na mente, idéias tão distintas quanto o cheiro ou a brancura do lírio; ou quanto o sabor do açúcar e o cheiro da rosa. $\mathrm{E}$ nada é mais evidente para o homem do que as 


\section{4}

percepções claras e distintas que ele tem das idéias simples que, sendo em si mesmas não-compostas, contêm apenas uma aparência, ou concepção uniforme, que não é distinguível em diferentes idéias" (LO CKE, 1979, livro II, cap. 2).

N o entanto, o que Locke parece não levar em conta quando afirma essa percepção distinta das idéias que só existiriam unidas umas às outras, é o que H ume chamará mais tarde de distinção de raz ão, o que significa que as distinções que fazemos entre a cor e a extensão percebidas em conjunto - uma vez que de fato temos de poder determinar alguma distinção se quisermos dar sentidos diferentes aos termos "cor" e "extensão" - não se dão, no entanto, por uma distinção de fato, uma vez que, efetivamente, no mundo ou em nossa mente, uma cor, por exemplo, nunca se apresenta fora de uma determinada extensão. Sendo assim, mesmo percebendo o todo composto por extensão e cor, ou reproduzindo essa percepção ao lembrarmo-nos dela, também de maneira complexa, somos capazes de dirigir nossa atenção para uma das características percebidas ou pensadas ao fazermos a comparação entre esse complexo e qualquer outro. D esse modo, diz-nos H ume, "quando nos é apresentado um globo de mármore branco, recebemos apenas a impressão de uma cor branca disposta em uma certa forma, não sendo capazes de distinguir a cor da forma. Porém, observando, em seguida, um globo de mármore negro, e um cubo de mármore branco, e comparando-os com nosso primeiro objeto, encontramos duas semelhanças separadas, naquilo que antes parecia, e realmente é, completamente inseparável"2.

Por outro lado, no entanto, se Locke justifica a separabilidade das qualidades que existiriam unidas nos objetos porque elas seriam percebidas já distintamente pela mente, portanto segundo uma distinção de fato, a consideração dessas qualidades tomadas individualmente, abstraídas agora de suas particularidades temporais e espaciais, seria um trabalho realizado especificamente pela mente, na construção das noções gerais que englobariam vários indivíduos. A lém disso, para Locke, tais noções, como a de "homem", "animal", "ser vivo" etc., seriam o sinal de uma distinção radical entre o que existe como idéia e o que existe como percepção. Para Berkeley, tais distinções são completos contra sensos que, mascarados por armadilhas da linguagem, conduzem a uma má interpretação da realidade. 
É nesse contexto que Berkeley criticará a teoria da predicação dos termos gerais apresentada por Locke e que a questão da linguagem efetivamente entrará em cena. Se retomarmos a seqüência da argumentação desenvolvida por Berkeley na "Introdução" aos Prinápios, a partir do pará grafo 11 e até 024 , observaremos a importância dada por ele ao papel da linguagem na pressuposição da abstração e, portanto, a extrema necessidade de explicitar tal papel para poder combatê-lo. Necessidade e importância que de resto revelam-se no próprio objeto da "Introdução". O bservamos então que, após criticar a possibilidade da abstração, ao constatar a incapacidade, dele e dos demais homens, em "separar, umas das outras, ou conceber separadamente, aquelas qualidades que não podem existir assim separadamente" e em "conceber uma noção geral abstraindo de suas particularidades" (BER KELEY, 1979, § 10), Berkeley procede ao exame dos argumentos al egados em favor dessa abstração. E 0 primeiro argumento examinado é aquele alegado por Locke quando este apresenta 0 que acredita ser um sinal da diferença existente entre os homens e os animais. Com efeito, para Locke, a predicação dos termos gerais pressuporia a mediação de uma idéia geral abstrata sob a qual vários indivíduos particulares fossem subsumidos. Sendo assim, a própria existência dos termos gerais seria um sinal da capacidade de abstração do homem, justamente o que seria a marca distintiva entre a racionalidade humana e aquela que pode ser reputada a alguns animais, que se manteriam no nível das representações particulares.

Assim, B erkeley cita Locke: "Ter idéias abstratas é o que estabelece perfeita distinção entre os homens e os animais, uma vez que as faculdades dos animais jamais alcançam tal excelência. [...] Pois se eles chegam a ter idéias e não são meras máquinas (como pensam alguns) não podemos negar que em alguma medida fazem uso da razão. E a mim parece bastante evidente que alguns dentre eles, em algumas ocasiões, pensam assim como sentem, mas apenas idéias particulares, exatamente como as recebem dos sentidos. 0 s melhores dentre eles estão restritos a esses estreitos limites, e acredito que não tenham a faculdade de ampliá-los por nenhum tipo de abstração" (LOCKE, 1979, livro 2, cap. II, sec. 10-11). E acrescenta: "Estou de pleno acordo com o sábio autor de que a faculdade desses animais jamais poderia alcançar a abstração. $M$ as, sendo assi $m$, receio que grande parte daque- 
les que passam por homens teria de ser contado entre eles" (BER KELEY, 1979, § 11).

Para Berkeley, portanto, se houvesse alguma distinção demarcada pela capacidade da abstração, essa só poderia ser aquela existente entre 0 comum dos homens e os sábios, uma vez que ele próprio e, com ele, a maior parte da humanidade, não seriam capazes de ir além desse plano da representação particular. No entanto, todos, e desde a mais tenra idade, utilizam os termos gerais na comunicação mais banal do dia-a-dia, o que pode ser um forte indício a favor da suposição de que, afinal de contas, tal distinção não exista e de que tais termos não impliquem referências unívocas a noções abstratas, as quais, segundo o próprio Locke, "encerram dificuldades e não se revelam tão facilmente como costumamos imaginar" (LO CKE, livro IV, cap. 7, sec. 9).

Sendo assim, é preciso apresentar uma outra hipótese para a predicabilidade dos termos gerais. Berkeley o faz ao afirmar que "os termos tornam-se gerais não porque se tornam símbolos de uma idéia geral abstrata, mas [porque se tornam símbolos] de várias idéias particulares, cada uma das quais indiferentemente sugeridas à mente". É no domínio mesmo das proposições gerais da Ciência e da Geometria - consideradas os redutos da abstração - que Berkeley procurará demonstrar sua hipótese. Sendo assim, proposições como "a mudança de movimento é proporcional à força aplicada" ou "tudo o que é extenso é divisível" são gerais, assim como seus termos, não porque dizem respeito a uma idéia abstrata de movimento ou extensão, mas a cada movimento e extensão determinados individualmente, uma vez que o que está implicado na divisibilidade da extensão ou na relação entre força aplicada e mudança de movimento não é este determinado comprimento, trajetória ou velocidade, mas que os corpos aos quais elas se aplicam tenham um determinado comprimento, trajetória ou velocidade definidos. A universalidade presente nas proposições da Física, e também nas da Geometria, como Berkeley exemplificará em outra passagem, prescinde de uma idéia abstrata, em relação à qual as leis seriam demonstradas e a partir da qual elas estender-se-iam às idéias particulares que teriam dado origem a essa idéia abstrata. A universalidade desse tipo de proposição deve-se a aplicação da lei a cada uma daquelas idéias particularmente definidas. 
É preciso então desfazer esse mau costume, segundo Berkeley originário de considerações equivocadas sobre a linguagem e por muito tempo cultivadas pelos sábios, que supõe a união de cada um dos termos gerais da linguagem a uma única idéia, uma vez que, para tanto, seria necessário que fosse possível construir idéias abstratas. No entanto, a construção de tais idéias abstratas, a partir daquelas idéias sensíveis que necessariamente se apresentam com graus determinados de qualidades e quantidades, pressupõe 0 absurdo de querer pensar uma qualidade ou uma quantidade sem essa determinação e a inconsistência de transformar uma relação, a da universalidade, em uma realidade positiva. "Eu sei que muito se insiste em que todo conhecimento e demonstração diz respeito a noções universais, com o que eu concordo plenamente. $\mathrm{N} o$ entanto, não me parece que essas noções sejam formadas pela abstração, do modo acima referido. Tanto quanto eu entendo, a universalidade não consiste na natureza ou no conceito absoluto, positivo de alguma coisa, mas na relação que se estabelece entre coisas individuais assim significadas ou representadas" (BER KELEY, 1979, § 15).

Berkeley insiste: nem os termos gerais da linguagem têm como referente unívoco uma idéia geral abstrata, nem as definições restringem a significação do termo definido a uma única idéia; "na verdade, não há nada como uma significação definida e precisa anexada a qualquer termo geral, todos eles significam indiferentemente um grande número de idéias particulares" (idem, § 18). Assim, se procurarmos o significado correspondente à definição de triângulo como o de uma superfície plana compreendida entre três linhas retas, só o poderemos encontrar em inúmeras idéias particulares distintas, de superfícies com cores e tamanhos distintos, limitados por linhas de comprimentos distintos e graus de inclinações distintas etc.

Por todas as vias, portanto, Berkeley procura colocar o leitor de sobreaviso sobre o uso das palavras, procurando preparar o caminho para o grande passo que ele terá de dar adiante para acompanhar seu pensamento.

Essa "Introdução", portanto, deve funcionar como uma vacina para os erros em relação ao conhecimento a que a não consideração da natureza da linguagem pode nos levar (e leva-nos constantemente). N ela, Berkeley espera ter demonstrado que os termos gerais utilizados por nós para a comunicação do dia-a-dia não se referem a uma única idéia abstrata que intermediaria sua aplicação às idéias particulares às quais usualmente nos 
referimos. Ele espera ter demonstrado também que os termos científicos, tanto aqueles usados na Física quanto nas $M$ atemáticas e que envolvem definições precisas, tampouco têm como referentes idéias abstratas, mas várias idéias particulares. Portanto, além de demonstrar o que as palavras não significam, a saber, idéias abstratas, B erkeley está interessado em afirmar como os termos ganham significado, ou seja, em idéias particularmente determinadas. A ssim, no final da "Introdução", para resguardar esse critério de significação, Berkeley propõe que as investigações que então se seguirão se pautem pela consideração dessas idéias particulares, despidas daquelas palavras por tanto tempo a elas anexadas pelo uso constante, com o que ele espera, em primeiro lugar, esclarecer ou manter-se afastado das controvérsias puramente verbais às quais somos levados pela pressuposição das idéias abstratas. $M$ as, mais do que isso, Berkeley é explícito em afirmar algo aparentemente óbvio, a saber, que pela observação de minhas "idéias despidas das palavras", portanto livre de suas possíveis influências, eu posso esperar não me deixar "enganar pensando ter uma idéia que não tenho". Pois, para Berkeley, justamente o contrário ocorre quando não atentamos para o fato de que a generalidade instituída pela linguagem não é de conteúdo, mas de referência, quando não levamos em conta que cada termo é geral porque se refere a várias idéias particulares e não a uma idéia abstraída de suas particularidades: enganamo-nos, então, e pensamos possuir uma idéia que não possuímos, com receio, talvez, de vermos esvaziar-se o significado de termos por tanto tempo utilizados. Tais considerações, no entanto, poderão tornar-se mais concretas na própria argumentação que se desenvolve na Parte I dos P rinápios, quando, então, Berkeley dará corpo às considerações metodológicas ora propostas e relacionará explicitamente o equívoco da linguagem em questão com a pressuposição da substância material.

Assim, depois de anunciar à moda de Locke, logo no primeiro parágrafo dessa Parte I, que os objetos do conhecimento humano resumemse a idéias percebidas por um espírito e são por ele representadas pela simples cópia, divisão ou composição; e, no parágrafo segundo, distanciando-se então radicalmente de Locke, ao afirmar que esta substância espiritual, que percebe e age sobre as idéias, é a única existente, Berkeley terá de desenvolver sua crítica à substância material. 
0 primeiro argumento formalmente apresentado contra a suposição da matéria será justamente 0 da contradição inerente à suposição da existência de objetos sensíveis abstraídos da sua própria percepção por uma mente. "Luzes e cores, quente e frio, extensão e forma, em uma palavra, as coisas que vemos e sentimos, o que são a não ser inumeráveis sensações, noções, idéias ou impressões nos sentidos; sendo impossível separar, mesmo que em pensamento, qualquer uma delas da percepção? Para mim seria como separar uma coisa de si mesma".

Aqui parece ocorrer um curto- circuito entre a opinião da maioria dos homens, a dos novos filósofos e a do próprio Berkeley que exige atenção. $\mathrm{H}$ á, para Berkeley, uma falsa opinião que, segundo ele, seria estranhamente aceita por toda a humanidade. $Q$ ual seria? A de que as coisas no mundo existem independentemente de sua percepção por uma mente. $\mathrm{N}$ isso, portanto, Berkeley difere da maioria dos homens e dos próprios filósofos. No entanto, diz B erkeley, se bem observarmos, o que são, para os homens, essas coisas no mundo? São exatamente aquilo que percebemos pelos sentidos, a saber, casas, rios, montanhas, ou seja, certas composições de extensão de determinado tamanho, com determinadas forma e cor, que apresentam determinada resistência ao toque e que podem, por vezes, apresentar determinados tipos de movimento, som e cheiro; nisso parece que Berkeley concorda com a grande maioria, excetuando, talvez, os filósofos. Estes, com efeito, criticam o que lhes parece uma visão "ingênua" do senso comum e notam que, sob o exame da razão, a independência dos objetos sensíveis - afirmada por eles e pelo senso comum - é incompatível com sua redução às suas qualidades sensíveis - que Berkeley reputa a si próprio e também ao senso comum. Sendo assim, levando em conta a relatividade em que essas qualidades se apresentam, dependendo do observador e da posição desse observador, desejando salvar a identidade e independência dos objetos em relação a esse observador, os novos filósofos concluíram poder afirmar que essas configurações particulares de extensão, forma, tamanho, densidade, cor etc., juntamente com as possíveis trajetórias por elas descritas, existiriam apenas na mente desse observador. D ado que, apesar de sua relatividade, tais configurações não são criações desses observadores e possuem certas regularidades que possibilitam sua organização em um universo comum, terminaram por afirmar que existiria algo exterior a esses observadores 
que seria a realidade independente e a causa disso que por eles é percebido, ainda que tal realidade existisse para além de qualquer possibilidade de percepção. Sendo assim, dado que aquilo que varia na observação de um determinado objeto é uma determinada extensão, forma, solidez, cor, velocidade, trajetória de movimento etc., mas não o fato de terem sempre alguma extensão, forma, solidez e serem passíveis de algum movimento, procedem à separação, ou à abstração, daquelas qualidades determinadas dadas na experiência sensível e consideram como real algo subjacente a elas. $O$ ra, procede-se, segundo Berkeley, e também segundo H ume, à separação do inseparável - "Para mim, é como separar uma coisa dela mesma" - , à impossível abstração.

É bastante indicativo, nesse sentido, o fato de, ao argumentar contra a possibilidade de separação daquilo que é percebido de sua própria percepção, ou seja, ao fundamentar sua crítica à distinção entre o mundo material e 0 mundo sensível, que Berkeley reedite, agora no parágrafo quinto da Parte I dos Prinápios, a argumentação contra a abstração apresentada anteriormente na "Introdução", quando então ele se dizia capaz de conceber algo que nunca tivesse percebido anteriormente, mas que ao menos fosse possível existir ou perceber. Lá, Berkeley dizia ser capaz de imaginar a cabeça de um homem sem o restante do corpo, ou as mãos ou o nariz também separados - mas esses cabeça, mãos ou nariz imaginados teriam necessariamente alguma forma e cor particulares. A qui, Berkeley diz-se capaz de imaginar o tronco de um homem separado de seus membros, ou o perfume de uma rosa separado da própria rosa, mas que, da mesma forma como seria impossível para ele ver ou sentir alguma coisa sem a atual visão ou sentimento dessa coisa, também seria impossível conceber pelo pensamento qualquer coisa sensível sem aquelas determinações particulares próprias à percepção da coisa. M ais uma vez, portanto, B erkeley está considerando apenas a realidade das coisas naquilo que é determinado individualmente, ou seja, as coisas existem segundo aquele modo mesmo em que elas se apresentam na percepção; pensar coisas sensíveis indeterminadamente constitui, sempre, contra- senso.

Em resumo, "extensão", "movimento", "forma" são termos que têm como referentes características consideradas essenciais à realidade material e só ganham significado em percepções complexas e determinadas. Como então dizer que a extensão pode estar além dessas percepções se, 
fora dessas percepções, esgotam- se quaisquer condições de significação do termo, uma vez que se perde justamente aquilo que Ihe dá significado (idéias sensíveis particulares)? N ão há aqui como compreender Berkeley sem apelar para a evidência de tal argumento. Esse argumento, com efeito, pareceu-Ihe tão evidente que o fez acreditar que, ao levá-lo em conta, seria possível extirpar o materialismo em apenas sete parágrafos.

Portanto, a famigerada identificação das coisas do mundo com percepções em uma mente, inscrita no princípio da filosofia de Berkeley, segundo o qual, para as coisas, seu esse é perapi, poderia ser apenas a contra partida da negação da consideração dessas coisas sem suas determinações, assim como elas dão-se na experiência sensível (em última instância, a contrapartida da manutenção do princípio de não-contradição)? Pois não seria esse princípio mesmo que seria desrespeitado ao imaginar-se a existência de uma extensão que não é grande nem pequena, nem linear, nem superficial ou sólida, ou de um movimento nem rápido nem lento? E não é para esse tipo de contradição que Berkeley, a todo momento, chama nossa atenção ao repetir-se inúmeras vezes nesse sentido?

É compreensível que, para responder afirmativamente a essas questões, o leitor exija muito mais do que foi dito até agora. Fiquemos portanto apenas com a afirmação, por parte de Berkeley, da identidade entre os objetos e sua percepção, notando ainda que tal identidade não implica que tais objetos tenham sua existência identificada ou dependente daqueles indivíduos, os espíritos, que o percebem. Isso se segue ao desenvolvimento necessário da argumentação, quando Berkeley afirma, no parágrafo imediatamente posterior, o fato de que, se não existem na mente de um ou outro espírito criado, tais objetos devem necessariamente existir na mente de algum espírito infinito. B erkeley apresenta, portanto, aquilo que ele considera como causa necessária de nossas percepções que, para ele, demonstrada a falácia da suposição da matéria, coloca-se como conseqüência de uma verdade evidente, a saber: " $Q$ ue tudo o que há no céu e na terra, em uma palavra, todos aqueles corpos que compõem a extraordinária máquina do universo, não subsistem fora da mente, que seu ser é ser percebido ou conhecido; e que, conseqüentemente, quando não estão sendo percebidos por mim, ou quando não existem em minha mente ou na de qualquer outro espírito criado, não têm qualquer existência, ou existem na mente de algum espírito eterno..." (idem, § 60). 
$\mathrm{N}$ ão continuaremos seguindo Berkeley no desenvolvimento de sua crítica à substância material e de sua argumentação em favor da causalidade divina contra a hipótese da causalidade inscrita na matéria. Parecenos que 0 que foi dito até aqui basta para levantar uma hipótese plausível sobre as relações existentes, para B erkeley, entre os maus usos sofridos pela linguagem e a postulação da matéria como algo distinto de sua percepção, conseqüentemente, as teorias da representação. Segundo essa hipótese, trata se efetivamente de uma má compreensão das estratégias da linguagem, por muito tempo alimentada, usar palavras que possuem vários referentes como se elas possuíssem um só. É um vício que tem sérias conseqüências quando levado adiante pelos responsáveis pelo desenvolvimento do conhecimento humano. Assim como estes reputam aos termos gerais da linguagem a referência a uma idéia em si mesma geral que não pode ser dada na experiência, mas que justamente é formada pela abstração daquilo que é dado em graus e quantidades definidas nessa mesma experiência, eles concebem uma espécie de hiper-realidade da experiência sensível abstraída dela mesma, dando-nos por meio dela, não mais o mundo, mas apenas um duplo, sua representação.

\footnotetext{
1 Princípios posteriormente formalizados por $\mathrm{H}$ ume, particularmente no Tratado da natureza humana, (HU M E, 2000, livro I, sec. 7).

2 “O que significa, então, uma distinção de razão, já que ela não implica nem diferença nem separação? Para eliminar tal dificuldade, devemos recorrer à explicação das idéias abstratas acima apresentada. É certo que a mente jamais teria sonhado em distinguir uma figura de um corpo figurado - uma vez que, na realidade, estes não são nem distinguíveis, nem separáveis -, se não houvesse observado que, mesmo nessa simplicidade, poderiam estar contidas várias semelhanças e relações diferentes. Assim, quando se nos apresenta um globo de mármore branco, recebemos apenas a impressão de uma cor branca disposta em uma certa forma, não sendo capazes de distinguir a cor da forma. Porém, observando, em seguida, um globo de mármore negro, e um cubo de mármore branco, e comparando- os com nosso primeiro objeto, encontramos duas semel hanças separadas, naquilo que antes parecia, e real mente é, completamente inseparável. Com a prática, começamos a distinguir a forma da cor por meio de uma distinção de razão. I sto é, consideramos a forma e a cor juntas, já que elas são de fato indistinguíveis e uma só coisa, mas a vemos também sob diferentes aspectos, de acordo com as semeIhanças de que são suscetíveis. Q uando queremos considerar apenas a forma do globo de mármore branco, formamos, na realidade, uma idéia tanto da forma quanto da cor, mas tacitamente dirigimos nossa atenção para sua semelhança com o globo de mármore negro. $\mathrm{E}$, do
}

doispontos, Curitiba, vol. 1, n. 2, p.57-73, jan/ jun, 2005 
mesmo modo, quando queremos considerar apenas sua cor, voltamos nosso olhar para sua semelhança com o cubo de mármore branco" (HU ME, 2000, livro I, parte I, sec.VIII).

\section{Referências bibliográficas}

BER K ELEY, G. 1979. A Treatise C oncerning the Principles of H uman K nowledge. In: T heW orks of $G$ eorge B erkeley B ishop of $C$ loyne. $E d$. by $A$.

A. Luce and T. E. Jessop.V. I-III. 2nd ed. London:T. N elson.

H U M E, D. 2000. Tratado da natureza humana. São Paulo: Imprensa O ficial do Estado de São Paulo.

LO CKE, J. 1979. A n E ssay C oncerning H uman U nderstanding. N ew York: 0 xford U niversity. 